\title{
Genetic Variation and Local Differentiation in the Pacific Cod Gadus macrocephalus Around Japan Revealed by mtDNA and RAPD Markers
}

\author{
Kenji Saitoh \\ Tohoku National Fisheries Research Institute Hachinohe Branch, Samemachi, Hachinohe 031-0841, Japan \\ (Received November 14, 1997)
}

\begin{abstract}
This study deals with local differentiation in Pacific cod among three Japanese coastal areas around putative reproductive sites and the western Bering Sea. Restriction and SSCP analyses conducted on the mitochondrial control region showed genetic divergence between some Japanese coastal areas and the Bering Sea. RAPD analysis also indicated divergence between Japanese coastal areas and the Bering Sea. mtDNA analysis revealed low variability and no local distinction among Japanese localities. Calculating gene frequency data sets by two different ways, RAPD markers showed accordance between genetic and geographic distances in Japanese coastal areas.
\end{abstract}

Key words: biodiversity, genetic distance, control region, random amplified polymorphic DNA, resource management, single-strand conformation polymorphism, stock identification

If fishery stocks can be precisely identified, fishery resource management practices can be improved. Stock identification enables regulations of fishing efforts for different stocks that fluctuate independently. We can also control stock enhancement by hatchery practices in genetically correct ways to minimize alteration of locally adapted gene pools.

Pacific cod Gadus macrocephalus is an important fisheries resource in the northern part of Japan. From 1976 to 1985 yearly landings of this species around Japan were at least 850 thousand tons. ${ }^{1}$ In the next decade however, annual landings declined to about 490-760 thousand tons. Hatchery projects aimed at stock enhancement began to try to compensate for this decline. Genetic study of Pacific cod around Japan is therefore necessary for proper stock management and enhancement.

This study provides some basic data for stock structure and local differentiation of Pacific cod around Japan and the western Bering Sea.

\section{Materials and Methods}

\section{Sample Fish}

Numbers and localities of sample fish used in this study are as follows: 30 adults from off Noto-shima, Ishikawa Prefecture, February 1994 and February 1995 (NT); 20 adults from off Wakinosawa, Aomori Prefecture, December 25, 1993 (WK); 42 juveniles from off Joban, Fukushima Prefecture $\left(37^{\circ} 30^{\prime} \mathrm{N}, 141^{\circ} 21^{\prime} \mathrm{E}\right)$, June $16,1995(\mathrm{JB})$; and 16 adults from the Bering Sea off Kamchatka Peninsula $\left(59^{\circ} 14^{\prime} \mathrm{N}, 166^{\circ} 07^{\prime} \mathrm{E}\right)$, December 24,1993 (BR). The NT and WK localities are major reproductive areas around Japanese coastal regions. ${ }^{2-5)}$ Eggs and sperm releasing individuals obtained from these localities were of coastal fishery landings. Specimens from the JB locality were juveniles caught by a trawling research vessel, the Wakata- ka Maru, Tohoku National Fisheries Research Institute. They were possibly descendants from a spawning group that migrated into Sendai Bay. ${ }^{6}$ Specimens from the BR locality came from trawl fishery landing.

\section{DNA Techniques}

Total genomic DNA extraction from muscle tissue followed the method using TNES-Urea buffer. ${ }^{7}$ Forceps and scissors for removing tissue were placed in a flame for a few seconds before dissecting new specimens to avoid contamination.

PCR primers for amplification of mitochondrial control region were as follows: 1) 5'CGGGAATTCTAAATTTAAACTACC3', 2) 5'ACTCCCCATGCCGGGCGTTCT3', 3) 5'CATTAGAAAGAACGCCCGGC3', and 4) 5'GGGGAATTCCATCCTAATATCTTCAGTA3' (Fig. 1). Primer \#1 is a modification of codrep $1 .^{8)}$ The $3^{\prime} 12 \mathrm{nt}$ portion of primers \#2 and 3 are complimentary and at the same position in the central domain of the control region. Therefore, PCR products with primers \#1 and 2 (left domain, about $530 \mathrm{bp}$ ), and with $\# 3$ and 4 (right domain, about $490 \mathrm{bp}$ ) cover the entire control region of about $1 \mathrm{~kb}$ that is amplifiable with primers \#1 and 4 .

A $50 \mu \mathrm{l}$ of the PCR reaction mixture contained $100 \mathrm{ng}$ of template DNA, $200 \mathrm{nmol}$ of each dNTP, $50 \mathrm{pmol}$ of each primer, $0.25 \mathrm{U}$ of recombinant Taq DNA polymerase and $1 \times$ reaction buffer (Takara, Japan). The $30-35$ cycles of the PCR reaction each consisted of $30 \mathrm{~s}$ at $94^{\circ} \mathrm{C}, 30 \mathrm{~s}$ at $55-62^{\circ} \mathrm{C}$ and $120 \mathrm{~s}$ at $72^{\circ} \mathrm{C}$. The PCR reactions started after initial denaturation for $120 \mathrm{~s}$ at $94^{\circ} \mathrm{C}$ and stopped after a final extension for $300 \mathrm{~s}$ at $72^{\circ} \mathrm{C}$. For amplification of the entire control region and the left domain, a 30-cycle reaction and an annealing temperature of $55^{\circ} \mathrm{C}$ were employed. For the right domain amplification, a 35 -cycle reaction with an annealing temperature of $62^{\circ} \mathrm{C}$ gave good results. 


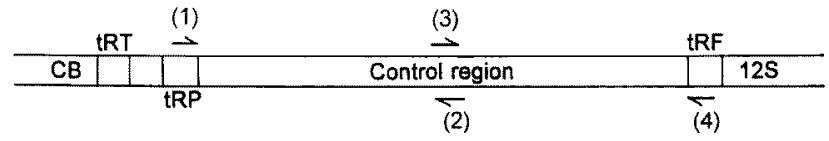

Fig. 1. Map of mitochondrial control and flanking regions showing position and direction (arrows) of PCR primers.

$12 \mathrm{~S}$, mitochondrial small subunit ribosomal RNA gene; $\mathrm{CB}$, cytochrome $b$ gene; tRF, tRP, and tRT, transfer RNA genes for phenylalanine, proline, and threonine respectively.

One $\mu l$ aliquots of the PCR product received digestion by one of the following restriction endonucleases for RFLP analysis: HaeIII, Hhal, HinfI, NdeII (Nippon Gene, Japan), MspI, Tru9I (Boehringer Mannheim, Germany), AluI, and TspEI (Toyobo, Japan). Reaction conditions followed the suppliers' recommendations. Reaction mixtures underwent electrophoresis in $2 \%$ agarose-L (Nippon Gene, Japan) in TAE ( $40 \mathrm{~mm}$ Tris-acetate, $1 \mathrm{~mm}$ EDTA, pH 8.0) and ethidium-bromide staining.

To make SSCP-loading samples, $1 \mu \mathrm{l}$ of PCR products of the left and right domains were respectively mixed with $5 \mu \mathrm{l}$ of loading dye $(0.15 \%$ bromophenol blue, $1.5 \%$ blue dextran, $50 \%$ formamide, $30 \mathrm{~mm}$ EDTA, $\mathrm{pH} \mathrm{7.2).} \mathrm{The}$ samples were boiled for 3-4 min and then quickly chilled. They were then ran in a $5 \%$ polyacrylamide-bis (49:1) gel containing $10 \%$ glycerol in $0.5 \times$ TBE $(45 \mathrm{mM}$ Tris-borate, $1 \mathrm{mM}$ EDTA, $\mathrm{pH} 8.3$ ) for $15 \mathrm{~h}$ at $12.5 \mathrm{~V} / \mathrm{cm}$ at $20^{\circ} \mathrm{C}$. DNA fragment detection was performed by silver staining (Wako, Japan).

Primers for RAPD analysis were as follows: 5) 5'TCTACGGTCA3', 6) 5'TCTAGAGCGT3', 7) 5'TCTGACACGA3', and 8) 5'TGGTCACTGA3'. The RAPD-primers were of desalted and gel-filtrated grade quality (Bio-Synthesis, USA). A $50 \mu l$ of the RAPD-PCR reaction mixture contained $100 \mathrm{ng}$ of template DNA, 200 nmol of each dNTP, $100 \mathrm{pmol}$ of either primer, $0.25 \mathrm{U}$ of ExTaq DNA polymerase and $1 \times$ reaction buffer (Takara, Japan). The 40 cycles of the RAPD-PCR reaction each consisted of $30 \mathrm{~s}$ at $94^{\circ} \mathrm{C}, 60 \mathrm{~s}$ at $37^{\circ} \mathrm{C}$, and $120 \mathrm{~s}$ at $72^{\circ} \mathrm{C}$ with initial denaturation for $120 \mathrm{~s}$ at $94^{\circ} \mathrm{C}$ and a final extension for $600 \mathrm{~s}$ at $72^{\circ} \mathrm{C}$. Conditions for electrophoresis and detection were the same as for RFLP analysis.

\section{Data Handling}

Estimation of mitochondrial haplotype diversity within locality followed Nei and Tajima. ${ }^{9}$ Probability estimation of haplotype frequency diversity among localities followed Roff and Bentzen ${ }^{10)}$ using computer software (Matsuishi, unpublished). The simulation was repeated 1000 times to give the estimated probability.

Variation detected by RAPD-PCR was analyzed by both the conventional band sharing index (BSI) ${ }^{11)}$ and gene frequency estimations for each RAPD 'locus'. Estimation of gene frequencies for RAPD loci was based on the assumption of a two-allele system. Of the two alleles, only one is capable of amplification of a RAPD-band by primer-annealing at an unknown genomic position (locus). The other is the 'null' allele incapable of amplification, mainly because of loss of the primer-annealing site by mutation. The two-allele assumption is in most cases acceptable, because codominant loci showing band shifts are few. ${ }^{12,13)}$ In this system only a null-homozygote is detectable as negative for the RAPD-band of interest. Under the assumption of Hardy-Weinberg equilibrium, the null allele frequency $(q)$ may be $(N / n)^{1 / 2}$, where $N$ and $n$ are the number of band-negative individuals observed and the sample size, respectively. The frequency of the other allele $(p)$ is $1-q$. This assumption of the two-allele system enables us to calculate the Nei's genetic distance ${ }^{14)}$ from the RAPD pattern.

When $N$ is small, however, estimate of $q$ has a downward bias. Lynch and Milligan ${ }^{15)}$ described an asymptotically unbiased estimator of $q(\hat{q})$ and an unbiased estimator of $D(\hat{D})$ for RAPD analysis. Under their assumptions, the bias of $\hat{q}$ is negligible when $N / n \geqq 1-3 / N$.

\section{Results}

\section{RFLP Analysis}

Eight restriction endonucleases revealed 20 restriction sites in the entire mitochondrial control region (Fig. 2). Because all the sites have specific 4 bp sequences, RFLP analysis detected variation along $80 \mathrm{bp}$ sequence equivalent. Variability in this region revealed by RFLP was low. There were only two variable sites among the 20 sites detected. Variant types (type-b of HaeIII and MspI in the figure) appeared commonly in two individuals from the JB locality. These individuals were the only two carrying the variant haplotype among the 108 individuals examined. The rest were of the major haplotype. Unlike Atlantic cod Gadus

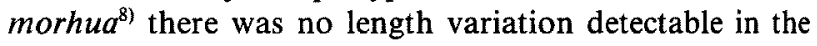
control region.

\section{SSCP Analysis}

SSCP electrophoresis revealed more variations than RFLP (Fig. 3). Combination of 6 and 2 types detected respectively from the left and right domains sorted 7 haplotypes among 108 individuals examined (Table 1). SSCP electrophoresis under the condition used in this study however, could not detect the base substitutions revealed by RFLP.

As some base substitutions were actually undetectable in this study, it is useful to deal with SSCP and RFLP haplotypes together for haplotype frequency analysis. Localization of both the variable restriction sites were in the left domain (Fig. 4), indicating the variant RFLP haplotype as the 7 th type of the left domain. Thus 8 haplotypes were distinguishable (Table 1). Imbalance in haplotype frequency prevailed also upon the SSCP-RFLP combination as revealed by RFLP. Estimation of haplotype diversity indicated low genetic divergence within localities.

A haplotype frequency comparison made by Monte Carlo simulation showed a significant difference between the JB and BR localities ( $p=0.0070 \pm 0.0026)$. The difference between the BR locality and the sum of NT and JB localities was also significant $(p=0.043 \pm 0.0064)$. The BR locality and the Japanese three localities altogether were not significantly different $(p=0.13 \pm 0.011)$. This may be partly due to the small sample size from the WK and BR localities. Though there was no stock distinction under the $5 \%$ risk rate among Japanese coastal areas, WK and JB localities were marginally different $(p=0.076 \pm 0.0084)$. 


\section{RAPD Analysis}

RAPD-PCR with four different primers gave 94 band positions on the gel, 20 to 27 per each primer. However, it was not clear if an amplified band was present or absent at many sites. Therefore I selected 34 unambiguous band positions for analyses. Because RAPD-PCR employs relaxed annealing conditions for short primers, one would expect low reproducibility due to nonspecific amplification. Amplification however, from the same template DNA or even from a different batch of template from the same individual with a different batch of reagents produced the same pattern (Fig. 5). This indicates high reproducibility in the reaction condition of this study. However, template DNA from four individuals from the BR locality and one from the NT locality showed poor amplification, possibly because of template degradation. These individuals were omitted from further analyses.

RAPD products with four primers used in this study showed some individual variation. RAPD product with primer \#6 revealed a difference between the BR and Japanese localities (Fig. 6). All but one individual among the 12 from the BR locality exhibited band-a, while none

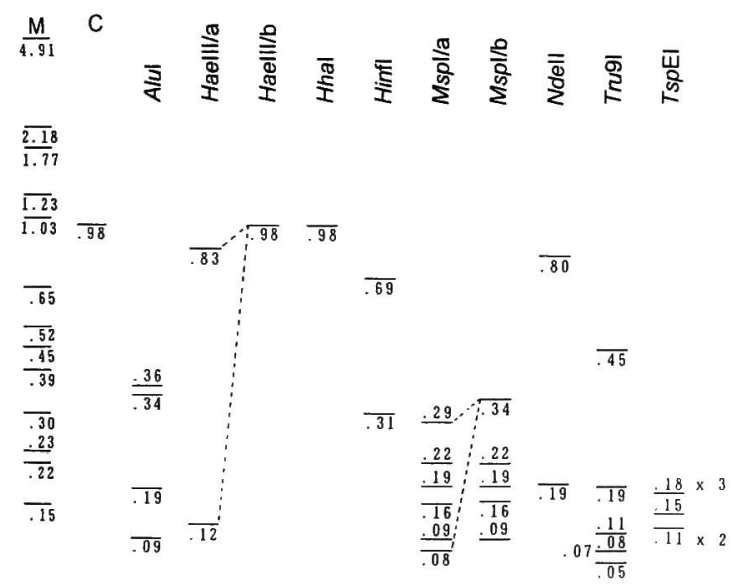

Fig. 2. Diagrammatic representation of restriction fragments of mitochondrial control region from Pacific cod showing putative sitegains or losses in HaeIII and MspI-digestion.

Fragment lengths are shown in $\mathrm{kb}$. M, molecular weight marker (Bam HI-digested pBR328 and marker VI, Boehringer Mannheim); C, uncut PCR product.
Table 1. Mitochondrial haplotypes detected by RFLP (type-g of the left domain) and SSCP of control region of Pacific cod

\begin{tabular}{|c|c|c|c|c|c|c|}
\hline \multirow{2}{*}{ Haplotype } & \multirow{2}{*}{$\begin{array}{c}\text { Left } \\
\text { domain }\end{array}$} & \multirow{2}{*}{$\begin{array}{l}\text { Right } \\
\text { domain }\end{array}$} & \multicolumn{4}{|c|}{ Locality* } \\
\hline & & & NT & WK & JB & BR \\
\hline 1 & $a$ & a & 25 & 14 & 35 & 9 \\
\hline 2 & $\mathrm{a}$ & b & 5 & 5 & 2 & 6 \\
\hline 3 & b & b & 0 & 1 & 0 & 0 \\
\hline 4 & $\mathrm{c}$ & $\mathrm{a}$ & 0 & 0 & 1 & 0 \\
\hline 5 & $\mathrm{~d}$ & $\mathrm{a}$ & 0 & 0 & 1 & 0 \\
\hline 6 & e & a & 0 & 0 & 0 & 1 \\
\hline 7 & $\mathrm{f}$ & a & 0 & 0 & 1 & 0 \\
\hline 8 & g & a & 0 & 0 & 2 & 0 \\
\hline \multicolumn{3}{|c|}{ Haplotype diversity $(\hat{h})$} & .283 & .456 & .303 & .557 \\
\hline
\end{tabular}

* BR, Bering Sea; JB, Joban; NT, Noto-shima; WK, Wakinosawa

from Japanese localities displayed the band except one from the JB locality. Of the 91 individuals from Japanese localities, 77 exhibited band-b, while only one from the BR locality showed the band. These bands may be 'marker' bands to distinguish the BR locality from Japanese localities.

Cluster analysis based on individual BSI values by UPG-

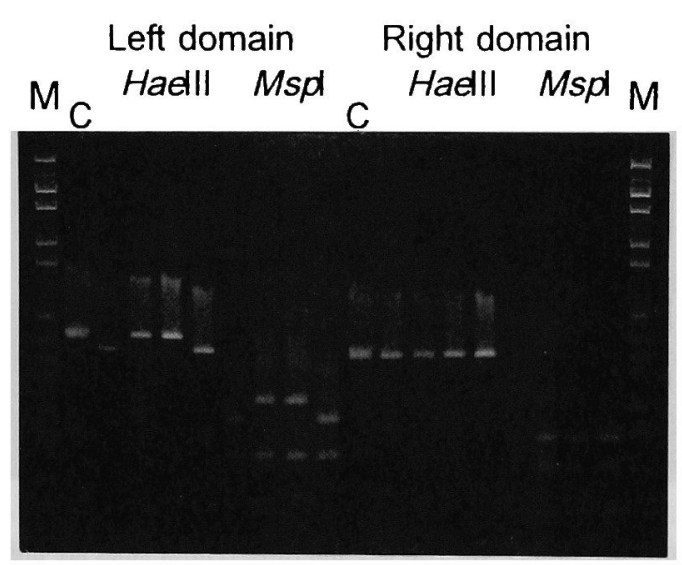

Fig. 4. Localization of variable restriction site to the left domain of mitochondrial control region.

Two central lanes are of variant type for each enzyme. M, molecular weight marker (BamHI-digested pBR328 and marker VI, Boehringer Mannheim); C, uncut PCR product.
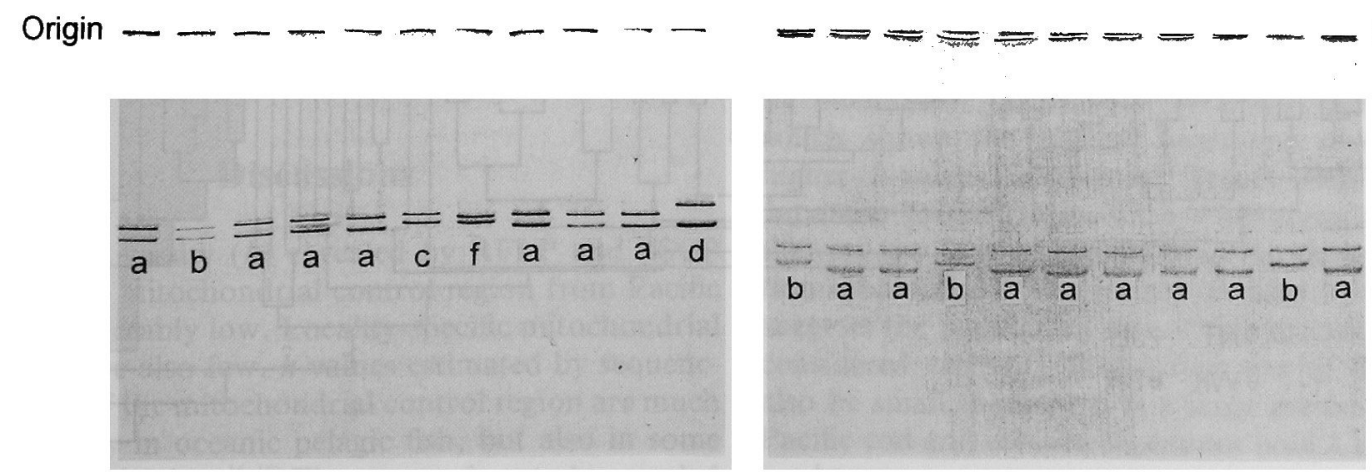

Fig. 3. SSCP electrophoresis pattern of left (left) and right (right) domains of mitochondrial control region from Pacific cod. Alphabets correspond types shown in table 1. 
MA showed a complex nested clustering of individuals from different localities (Fig. 7). There was no cluster containing any samples from a single locality and excluding ones from other. However, all but one individual from the BR locality were in a hatched cluster that contained only two from other localities. This suggests a population distinction between the BR and Japanese localities.

Comparison of RAPD patterns by BSI is not genetic, but rather similar to that based on morphology, in spite of some genetic basis. For population studies it is better to convert a RAPD pattern into gene frequency through assumptions such as the two-allele system (Table 2).

Unbiased estimation of genetic distance between populations based on a less biased estimation of gene frequencies on RAPD loci showed concordance between genetic and geographic distances among Japanese localities (Table 3). Seven to 11 loci that passed over the $1-3 / N$ threshold by population pair in comparison worked for $\hat{D}$-value calculation. No selected loci showed significant differences in gene frequencies between localities. Unlike the results from BSI and mitochondrial haplotype comparisons, however, the
BR locality showed no evidence for population distinction from the Japanese localities.

The $1-3 / N$ threshold $^{15)}$ discards loci of replaced bands that may be markers for population distinction. Band-a with primer $\# 6$ actually does not work for estimation of $\hat{D}$ in comparisons with BR locality, though it does work among Japanese localities. Band-b is neither useful among any comparisons. Many selected loci may then have similar gene frequencies between populations. This will result in an underestimation of genetic distance, especially between distantly related populations. It is, therefore, also worthwhile to calculate $D$-values without selecting loci.

Estimation of standard genetic distance between populations with unmodified $q$-values for 34 loci showed a comparable situation among Japanese localities (Table 3). The BR locality was nearly equally distant from the Japanese localities $($ mean $=0.103)$, while Japanese localities were much closer each other $($ mean $=0.013)$. The $D$-value may, however, be an overestimation, especially between localities with large differences in RAPD-patterns.

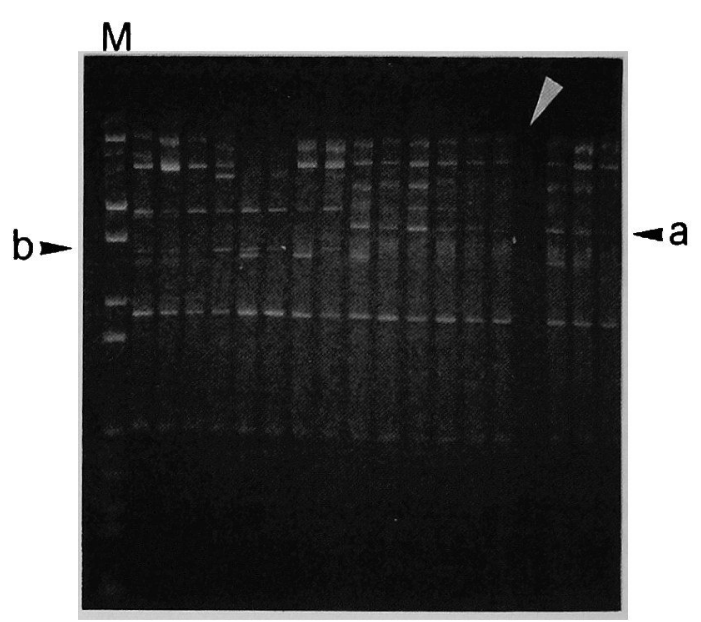

Fig. 6. RAPD pattern with primer \#6.

Bands- $a$ and $b$ are 'marker' bands for discrimination of individuals from Japanese localities (lane 2-9) and from the Bering Sea (lane 10-19). Individual indicated by an arrowhead showed poor amplification and was omitted from analysis. M, molecular weight marker (Bam HI-digested pBR328 and marker VI, Boehringer Mannheim).

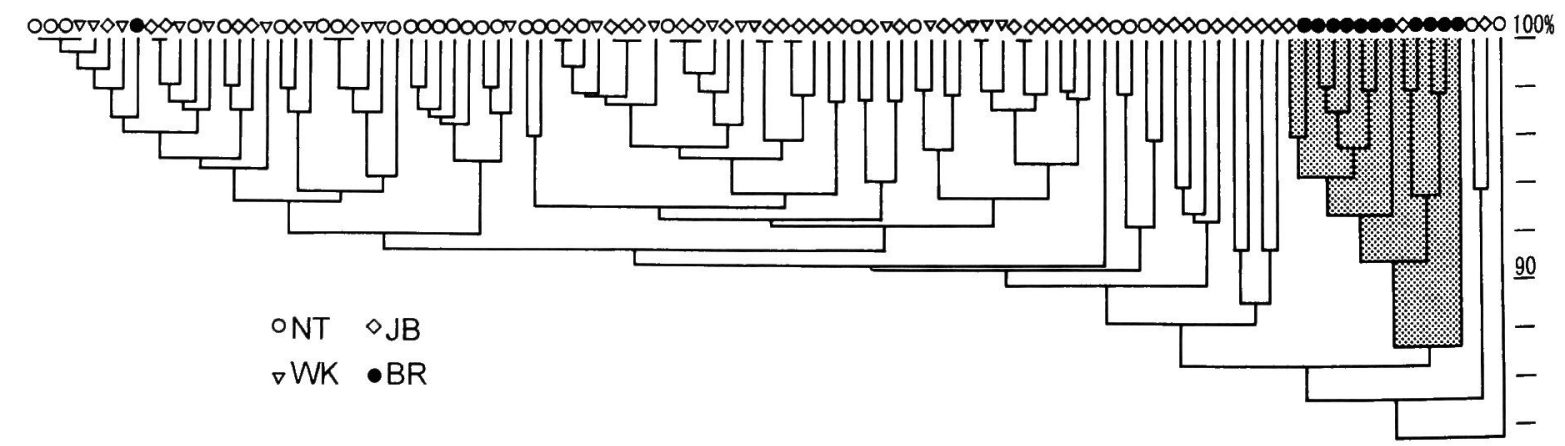

Fig. 7. Individual similarity exhibited by UPGMA tree based on BSI value of RAPD pattern. Hatched cluster shows cohesion of individuals from the Bering Sea. 
Table 2. Phenotype distribution of RAPD-PCR pattern (frequency of band observed) and less biased estimation of gene frequency ( $\hat{q}$ ) of RAPD loci (within parentheses) of Pacific cod

\begin{tabular}{|c|c|c|c|c|c|}
\hline \multirow{2}{*}{\multicolumn{2}{|c|}{$\begin{array}{l}\text { Primer/ } \\
\text { Band size } \\
\text { in } k b\end{array}$}} & \multicolumn{4}{|c|}{ Locality } \\
\hline & & \multirow{2}{*}{$\frac{\mathrm{NT}}{.200(.896)}$} & \multirow{2}{*}{$\frac{\text { WK }}{.000(1.000)}$} & \multirow{2}{*}{$\begin{array}{c}\text { JB } \\
.091(.954)\end{array}$} & \multirow{2}{*}{$\frac{\mathrm{BR}}{.000(1.000)}$} \\
\hline \#5 & 2.22 & & & & \\
\hline & 2.17 & $.280(.851)$ & $.176(.909)$ & $.121(.938)$ & $.000(1.000)$ \\
\hline & 2.03 & $1.000\left(\right.$ n.d. $\left.^{* 1}\right)$ & $1.000($ n.d.) & 1.000 (n.d.) & 1.000 (n.d.) \\
\hline & 1.69 & $.480(.728)$ & $.353(.809)$ & $.091(.954)$ & $.083(.958)$ \\
\hline & 1.59 & $.360(.804)$ & $.235(.877)$ & $.394(.782)$ & .583 (n.d.) \\
\hline & 1.10 & .880 (n.d.) & .824 (n.d.) & .758 (n.d.) & .583 (n.d.) \\
\hline & 1.00 & .680 (n.d.) & $.824($ n.d.) & $.333(.819)$ & .583 (n.d.) \\
\hline \multirow[t]{7}{*}{ \#6 } & 3.03 & $.107(.945)$ & $.000(1.000)$ & $.167(.914)$ & $.000(1.000)$ \\
\hline & 2.13 & 1.000 (n.d.) & 1.000 (n.d.) & 1.000 (n.d.) & $.417(.774)$ \\
\hline & $1.84^{*_{2}}$ & $.000(1.000)$ & $.000(1.000)$ & $.024(.988)$ & .917 (n.d.) \\
\hline & $1.66^{* 3}$ & .929 (n.d.) & .850 (n.d.) & .810 (n.d.) & $.083(.958)$ \\
\hline & 1.17 & 1.000 (n.d.) & 1.000 (n.d.) & 1.000 (n.d.) & $1.000(\mathrm{n} . \mathrm{d})$. \\
\hline & .69 & 1.000 (n.d.) & 1.000 (n.d.) & 1.000 (n.d.) & .917 (n.d.) \\
\hline & .50 & $.000(1.000)$ & $.000(1.000)$ & $.000(1.000)$ & $.083(.958)$ \\
\hline \multirow[t]{10}{*}{$\# 7$} & 2.74 & 1.000 (n.d.) & 1.000 (n.d.) & .976 (n.d.) & .917 (n.d.) \\
\hline & 2.28 & 1.000 (n.d.) & 1.000 (n.d.) & $1.000($ n.d.) & .917 (n.d.) \\
\hline & 2.23 & $.069(.965)$ & $.150(.923)$ & $.195(.898)$ & $.083(.958)$ \\
\hline & 1.64 & .966 (n.d.) & 1.000 (n.d.) & 1.000 (n.d.) & 1.000 (n.d.) \\
\hline & 1.39 & 1.000 (n.d.) & 1.000 (n.d.) & 1.000 (n.d.) & $1.000($ n.d.) \\
\hline & 1.30 & 1.000 (n.d.) & 1.000 (n.d.) & 1.000 (n.d.) & $1.000($ n.d.) \\
\hline & .95 & 1.000 (n.d.) & 1.000 (n.d.) & 1.000 (n.d.) & $1.000($ n.d.) \\
\hline & .88 & 1.000 (n.d.) & 1.000 (n.d.) & 1.000 (n.d.) & 1.000 (n.d.) \\
\hline & .79 & 1.000 (n.d.) & $1.000($ n.d.) & 1.000 (n.d.) & $1.000($ n.d.) \\
\hline & .73 & 1.000 (n.d.) & 1.000 (n.d.) & 1.000 (n.d.) & 1.000 (n.d.) \\
\hline \multirow[t]{10}{*}{$\# 8$} & 2.20 & .966 (n.d.) & 1.000 (n.d.) & $.976($ n.d.) & 1.000 (n.d.) \\
\hline & 2.17 & $.379(.791)$ & $.100(.949)$ & $.119(.939)$ & $.750($ n.d.) \\
\hline & 1.69 & .793 (n.d.) & .650 (n.d.) & $.524(.695)$ & 1.000 (n.d.) \\
\hline & 1.65 & $.207(.892)$ & $.050(.975)$ & $.095(.952)$ & $.000(1.000)$ \\
\hline & 1.63 & .966 (n.d.) & .950 (n.d.) & 1.000 (n.d.) & $1.000($ n.d.) \\
\hline & 1.43 & 1.000 (n.d.) & 1.000 (n.d.) & 1.000 (n.d.) & 1.000 (n.d.) \\
\hline & 1.40 & .931 (n.d.) & 1.000 (n.d.) & .976 (n.d.) & 1.000 (n.d.) \\
\hline & 1.34 & $.448(.748)$ & .650 (n.d.) & $.548(.678)$ & 1.000 (n.d.) \\
\hline & .80 & 1.000 (n.d.) & .950 (n.d.) & .952 (n.d.) & 1.000 (n.d.) \\
\hline & .32 & .966 (n.d.) & 1.000 (n.d.) & 1.000 (n.d.) & 1.000 (n.d.) \\
\hline
\end{tabular}

*1 n.d., not determined for $N / n<1-3 / N$.

${ }^{*}, * 3$ bands-a and $-b$ in Fig. 6

Table 3. Unbiased $(\hat{D})$ and standard $(D)$ estimation of genetic distance between localities estimated from RAPD-PCR of Pacific $\operatorname{cod}$

\begin{tabular}{llllllll}
\hline & \multicolumn{3}{c}{$\hat{D}$} & & \multicolumn{4}{c}{$D$} \\
\cline { 7 - 8 } \cline { 6 - 7 } & \multicolumn{1}{c}{ NT } & WK & JB & & NT & WK & JB \\
\hline WK & $.007(10)$ & & & .012 & & \\
JB & $.018(11)$ & $.010(10)$ & & .016 & .012 & \\
BR & $.014(7)$ & $.006(7)$ & $.004(7)$ & .109 & .101 & .101 \\
\hline
\end{tabular}

Numbers in parentheses indicate number of loci selected.

\section{Discussions}

Haplotype diversity $(\hat{h})$ revealed by RFLP and SSCP analyses of the mitochondrial control region from Pacific cod was considerably low. Locality-specific mitochondrial haplotypes were also few. $\hat{h}$-values estimated by sequencing or RFLP of the mitochondrial control region are much higher not only in oceanic pelagic fish, but also in some coastal demersal fishes. ${ }^{16-19)}$ The sequencing study revealed 280-630 bp, and the RFLP studies did 116-216 bp equiva- lent judged from restriction patterns. Because the number and evenness of haplotypes affect the $\hat{h}$-value, we should compare this value with DNA of comparable length and mutability. Some coastal fishes however, showed moderate or even lower $\hat{h}$-values revealed by RFLP of the entire mitochondrial genome (about 200-400 bp comparison equivalent). ${ }^{20-23)}$ Sequencing of $307 \mathrm{bp}$ of the cytochrome $b$ gene from Atlantic cod also revealed a low $\hat{h}$-value. ${ }^{24)} \mathrm{Be}-$ cause these studies examined regions of medium or lower evolutionary rates, the values would be smaller than the control region.

The total analyzed length of SSCP electrophoresis of this study was about $1,000 \mathrm{bp}$, but the effective length should be shorter according to the sensitivity. Some authors estimated about 70 to $100 \%$ sensitivity for SSCP of about $200 \mathrm{bp}$ fragments. ${ }^{25-27)}$ The electrophoretic condition of the present study is especially effective. ${ }^{25)}$ SSCP technique also detects all variants for fish mitochondrial control regions, ${ }^{28,29}$ but in an extreme case no mobility shift occurred ${ }^{28}$ Because length of fragments for SSCP in the present study were longer than usual, sensitivity may be lower. If the sensitivity of this study is in between 0 and $70 \%$, SSCP of this study is comparable to a typing by about $<700$ bp sequence comparison. Combination with RFLP may then account for around $80-700 \mathrm{bp}$. This is comparable to the sequence lengths in studies listed above.

Genetic variability of Pacific cod represented by mitochondrial haplotype diversity is lower than among fishes. Isozyme data also shows low genetic variabilities among populations from the eastern Bering Sea and northeastern Pacific. ${ }^{30}$

Ecological characteristics of Pacific cod, such as population size, can explain only partly the low level of variability. Pacific cod are usually distributed off-shore around northern Japan. Migration to coastal area occurs in the spawning season. ${ }^{2,5)}$ In Mutsu Bay, yearly fishery landings of probable spawning groups of Pacific cod from 1976 to 1985 varied $217-649 \mathrm{t}^{31)}$ A tagging study showed about $5 \%$ recapture in the same season around the released sites. ${ }^{2}$ Average weight of adult female cod is about $4.3 \mathrm{~kg} .{ }^{3)}$ Assuming a release date in the middle of the fishing season, an even sex ratio, and no loss of tagged fish, the number of spawning females in Mutsu Bay may be around $250,000-750,000$, though overestimation is possible to some extent. This value is probably smaller than in oceanic pelagic fishes with high variabilities.

The estimated population size is, however, much larger than that of sturgeon Acipenser oxyrhynchus from an Atlantic area with a higher mitochondrial $\hat{h}$-value $(0.643){ }^{21}$ ) The number of spawning females is close to that of Atlantic menhaden Brevoortia tyrannus $(250,000-800,000)$ which shows the highest haplotype diversity. ${ }^{21)}$ Much higher $\hat{h}$-values in red sea bream Pagrus major and Japanese flounder Paralichthys olivaceus also contrast to the very low level of variability in Pacific cod. ${ }^{17-19)}$ Population subdivision of sea bream revealed by mtDNA typing suggests the population size of this species is smaller than considered earlier. ${ }^{17)}$ Population size of flounder should also be small, because it is a large predatory species like Pacific cod and ecosystems cannot hold a large number of predators.

The low level of mitochondrial haplotype diversity may 
be also due to geological demographic patterning of Pacific cod. A bottleneck event during the first migration of the ancestral population into the Pacific through the Bering Strait may be responsible for the low genetic variabilities. ${ }^{32)}$ It is also possible that population bottlenecks repeatedly occurred through late Diluvial ice-age cycles. Bottlenecks would be severe around Japanese coasts, because these areas are near the southern limit of the geographic range of the species.

Isozyme data indicates a population distinction between North American and Asian localities, though the location of their border is unclear. ${ }^{30)}$ The population division between the western Bering Sea and Japanese coastal areas collectively shown by mtDNA and RAPD markers suggests two possibilities; the North American-Asian boundary occurs between Kamchatka and Japan, or the western Bering Sea stock forms a third distinct population. Further study, however, is necessary with comparative samples from both North American and Asian localities to clarify the borders between populations.

Genetic distances estimated from RAPD markers using two methods both indicated concordance between genetic and geographic distances among Japanese localities with very small population divergence. mtDNA analysis also showed no distinction between Japanese localities. It then cannot exclude the possibility of a single, large population with clinal genetic variation of RAPD loci around the Japanese coasts. Such clinal variation can arise when a genetic equilibrium is being established through gene exchange between contiguous groups by migration. Some authors reported several small-scale spawning sites of Pacific cod around Japanese coastal areas other than the three major areas examined in this study. ${ }^{33-36)}$ The population structure of this species in Japanese coastal waters may be contiguous. Possible recent population bottlenecks through ace-age cycles might cause an intermediate stage of genetic structure of hybridizing subpopulations. Equilibrium between gene exchange by migration and selection upon some ecological trait loci associated with RAPD loci also can account for the clinal genetic variation. Pacific cod in the northwestern Pacific shows a clinal variation in size and age at maturity ${ }^{37}$ If this is due to local adaptation and has some genetic bases, the geographical genetic variation observed in this study may be an indication of such an equilibrium.

Even if the population structure of Pacific cod around Japan is contiguous to some extent, some discontinuity is also possible in population structure leading to population distinction. The WK and JB localities were marginally different in mtDNA haplotype frequency, suggesting some population subdivision occurs around Japanese coastal areas. Further study with extensive sampling is necessary to clarify whether genetic divergence among Japanese localities is clinal or indicates a distinct population subdivision. Regardless of the overall population structure of Pacific cod from Japanese coasts, this study gives no evidence for genetic identity among the Japanese localities analyzed. Introduction of parental fish from different localities in hatchery practices for stock enhancement should, therefore, be minimal and is not recommended.

Acknowledgments I express my cordial thanks to Nobuaki Arai of
Kyoto University, Hiroyosi Nakanishi and Toshiaki Wakutsubo of Aomori Prefectural Aquaculture Research Center, Kenzo Yoseda and Masato Kobayashi of Japan Sea-Farming Association Noto-shima Station, and the crew of the research vessel Wakataka Maru, Tohoku National Fisheries Research Institute for their help in sample collection. Special thanks go to Tadashi Inada, Yoshio Ishito, Daiji Kitagawa, $Y_{0}$ Yamashita, Ryozo Sato and Takanori Kobayashi for their comments and guidance. Takashi Matsuishi of Hokkaido University provided a computer program (ROFF.EXE) for mitochondrial haplotype frequency comparison.

\section{References}

1) Statistics and Information Department, MAFF: Statistics on fisheries and water culture production $(1986,1996)$ (in Japanese).

2) S. Fukuda, K. Yokoyama, Y. Hayakawa, and H. Nakanishi: On tagging experiments of adult Pacific cod in the entrance of Mutsu Bay, Aomori Prefecture. Saibai Giken, 14, 71-77 (1985) (in Japanese).

3) T. Hattori, Y. Sakurai, and K. Shimazaki: Fecundity of spawning Pacific cod (Gadus macrocephalus) in Mutsu Bay, Japan. Bull. Tohoku Natl. Fish. Res. Inst., 57, 1-5 (1995) (in Japanese)

4) T. Takatsu, T. Nakatani, T. Mutoh, and T. Takahashi: Feeding habits of Pacific cod larvae and juveniles in Mutsu Bay, Japan. Fish. Sci., 61, 415-422 (1995).

5) K. Yoseda, J. Hirokawa, Y. Nagakura, M. Aritaki, and M. Kobayashi: Maturity condition of adult Pacific cod and distribution of Pacific cod eggs, larvae and juveniles in adjacent waters of Notoshima, Ishikawa Prefecture, Japan. Saibai Giken, 21, 21-30 (1992) (in Japanese).

6) J. Kodama, H. Nagashima, and Y. Izumi: Ecology of Pacific cod inhabiting around Kinkazan Island. 200 Kairi Suiikinai Gyogyo Shigen Sogo Chosa 11th Tohoku Kaiku Sokouo Kenkyu Team Kaigi Kaigi Hokoku, 43-46 (1991) (in Japanese).

7) T. Asahida, T. Kobayashi, K. Saitoh, and I. Nakayama: Tissue preservation and total DNA extraction from fish stored at ambient temperature using buffers containing high concentration of urea. Fish. Sci., 62, 727-730 (1996).

8) E. Árnason and D. M. Rand: Heteroplasmy of short tandem repeats in mitochondrial DNA of Atlantic cod, Gadus morhua. Genetics, 132, 211-220 (1992).

9) M. Nei and F. Tajima: DNA polymorphism detectable by restriction endonucleases. Genetics, 97, 145-163 (1981).

10) D. A. Roff and P. Bentzen: The statistical analysis of mitochondrial DNA polymorphisms: $\chi^{2}$ and the problem of small samples. $\mathrm{Mol}$. Biol. Evol., 6, 539-545 (1989).

11) H.-S. Han, H. Mannen, A. Tsujimura, and N. Taniguchi: Application of DNA fingerprinting to confirmation of clone in ayu. Nippon Suisan Gakkaishi, 58, 2027-2031 (1992).

12) K. Elo, S. Ivanoff, J. A. Vuorinen, and J. Piironen. Inheritance of RAPD markers and detection of interspecific hybridization with brown trout and Atlantic salmon. Aquaculture, 152, 55-65 (1997).

13) J. Welsh and M. McClelland. Fingerprinting genomes using PCR with arbitrary primers. Nucleic Acids Res., 18, 7213-7218 (1990).

14) M. Nei: Genetic distance between populations. Am. Nat., 106, 283292 (1972).

15) M. Lynch and B. G. Milligan: Analysis of population genetic structure with RAPD markers. Mol. Ecol., 3, 91-99 (1994).

16) J. R. A. Bremer, A. J. Baker, and J. Mejuto: Mitochondrial DNA control region sequences indicate extensive mixing of swordfish (Xiphias gladius) populations in the Atlantic Ocean. Can. J. Fish. Aquat. Sci., 52, 1720-1732 (1995).

17) K. Tabata and A. Mizuta: RFLP analysis of the mtDNA D-loop region in red sea bream Pagrus major population from four localities of Western Japan. Fish. Sci., 63, 211-217 (1997).

18) T. Fujii and M. Nishida: High sequence variability in the mitochondrial DNA control region of the Japanese flounder Paralichthys olivaceus. Fish. Sci., 63, 906-910 (1997).

19) T. Asahida, K. Saitoh, Y. Yamashita, Y. Aonuma, and T. Kobayashi: Genetic variation in the Japanese flounder based on 
analysis of mitochondrial DNA by restriction endonucleases. Nippon Suissan Gakkaishi, 64, 377-383 (1998) (in Japanese).

20) D. Crosetti, W. S. Nelson, and J. C. Avise: Pronounced genetic structure of mitochondrial DNA among populations of the circumglobally distributed grey mullet (Mugil cephalus). J. Fish. Biol, , 44, 47-58 (1994).

21) B. W. Bowen and J. C. Avise: Genetic structure of Atlantic and Gulf of Mexico populations of sea bass, menhaden, and sturgeon: influence of zoogeographic factors and life-history patterns. Mar. Biol., 107, 371-381 (1990).

22) J. E. Graves, J. R. McDowell, and M.L. Jones: A genetic analysis of weakfish Cynoscion regalis stock structure along the mid-Atlantic coast. Fish. Bull., 90, 469-475 (1992).

23) W. Stott, M. M. Ferguson, and R. F. Tallman: Genetic population structure of American plaice (Hippoglossoides platessoides) from the Gulf of St. Lawrence, Canada. Can. J. Fish. Aquat. Sci., 49, 2538-2545 (1992).

24) S. M. Carr, A. J. Snellen, K. A. Howse, and J. S. Wroblewski: Mitochondrial DNA sequence variation and genetic stock structure of Atlantic cod (Gadus morhua) from bay and offshore locations on the Newfoundland continental shelf. Mol. Ecol., 4, 79-88 (1995).

25) K. Hayashi and D. W. Yandell DW: How sensitive is PCR-SSCP? Hum. Mutat., 2, 338-346 (1993).

26) V. C. Sheffield, J. S. Beck, A. E. Kwitek, D. W. Sandstrom, and E. $M$. Stone: The sensitivity of single-stranded conformation polymorphism analysis for the detection of single base substitutions. Genomics, 16, 325-332 (1993).

27) H. K. Jensen, L. G. Jensen, P. S. Hansen, O. Faergeman, and N Gregersen: High sensitivity of the single-strand conformation polymorphism method for detecting sequence variations in the low-density lipoprotein receptor gene validated by DNA sequencing. Clin. Chem., 42, 1140-1146 (1996).

28) L. Ostellari, L. Bargelloni, E. Penzo, P. Patarnello, and T. Patarnello: Optimization of single-strand conformation polymor- phism and sequence analysis of the mitochondrial control region in Pagellus bogaraveo (Sparidae, Teleostei): Rationalized tools in fish population biology. Anim. Genet., 27, 423-427 (1996).

29) I. Oohara: Detection of single strand conformation polymorphisms (SSCPs) on mitochondrial DNA fragments between two domesticated strains of rainbow trout Oncorhynchus mykiss. Fish. Sci., 63, 151-152 (1997).

30) W. S. Grant, C. I. Zhang, T. Kobayashi, and G. Ståhl: Lack of genetic stock discretion in Pacific cod. Can. J. Fish. Aquat. Sci., 44, 490-498 (1987).

31) Aomori Statistics \& Information Office, Tohoku Regional Agracultural Administration Office, MAFF: Annual Statistics on fisheries in Aomori Prefecture (1976-1985) (in Japanese).

32) W. S. Grant and G. Stảhl: Evolution of Atlantic and Pacific cod: loss of genetic variation and gene expression in Pacific cod. Evolution, 42, 138-146 (1988).

33) R. Hashimoto and $S$. Abe: On juveniles of walleye pollock and Pacific cod in Tohoku region. Sokouo Joho, 31, 9-15 (1962) (in Japanese).

34) C. Fujisawa and M. Natsume: Migration of adult Pacific cod, $G a-$ dus macrocephalus, from Kikonai Bay, southern Hokkaido, Japan. Sci. Rep. Hokkaido Fish. Exp. Stn., 47, 25-31 (1995) (in Japanese).

35) S. Shibata: Report of rsearches on factors influencing ocurrence of coastal fishery fields: ecology and resource of Pacific cod. Akitaken Suisan Shinko Center Jigyo Hokokusho, 1991, 79-86 (1992) (in Japanese).

36) T. Tadahachi, M. Sato, and S. Aotsuka: Report of research and development of important local new fisheries technology: ecology and resource of Pacific cod. Yamagata-ken Suisan Shikenjo Jigyo Hokoku, 1992, 25-26 (1994) (in Japanese).

37) T. Hattori, Y. Sakurai, and K. Shimazaki: Regional differences in size at maturity in Pacific cod. 200 Kairi Suiikinai Gyogyo Shigen Sogo Chosa 14th Tohoku Kaiku Sokouo Kenkyu Team Kaigi Kaigi Hokoku, 1-13 (1994) (in Japanese). 